\title{
Assessment of Outcome of Intrathecal Analgesia in Multiparous Women Undergoing Vaginal Delivery
}

\author{
Sanjay Melville Masih ${ }^{1}$, Rakesh Kumar Gupta ${ }^{2}$ \\ ${ }^{1}$ Associate Professor, Department of Anaesthesiology, FH Medical College, Tundla, India, ${ }^{2}$ Assistant Professor, Department of Anaesthesiology, FH \\ Medical College, Tundla, India.
}

\section{Abstract}

Background: The present study was conducted to assess the outcome of intrathecal analgesia in multiparous women undergoing vaginal delivery. Subjects and Methods: The present study was conducted among 80 multiparous women ages ranged 18 - 40 years. All patients received 0.5 ml of intrathecal injection of $2.5 \mathrm{mg}$ bupivacaine $0.5 \%$ and $1 \mathrm{ml}$ dexamethasone $4 \mathrm{mg}$ plus a $0.5 \mathrm{ml}$ adjuvant. The adjuvants in group I patients were $100 \mu \mathrm{g}$ morphine, $25 \mu \mathrm{g}$ fentanyl in group II, $5 \mu \mathrm{g}$ dexmedetomidine in group III and normal saline in group IV (control group). The primary and secondary outcome was the duration of pain relief, the analgesia onset time, the maximum level of sensory block, the visual analogue scale (VAS) was recorded. Results: The mean duration of analgesia in group I was 182.4 minutes, in group II was 170.5 minutes, in group III was 200.4 minutes and in group, IV was 140.2 minutes. The onset of analgesia was 3.9 minutes, 2.8 minutes, 2.7 minutes and 4.5 minutes in group I, II, III and IV respectively. S1 sensory regression time (minutes) was 181.4, 157.4, 185.3 and 130.6 in group I, II, III and IV respectively. Modified Bromage scale 5 minutes, 15 minutes and 30 minutes after IT in all groups was 0.0. VAS was 1.3, 1.6, 1.6 and 3.1 with significant differences in all groups $(\mathrm{P}<0.05)$. There was non- significant difference in mean age, weight, height and gestational age between all groups $(\mathrm{P}>$ 0.05). There was a non- significant difference in APGAR 1, 5, umbilical $\mathrm{pH}$ immediately after delivery, neonatal HR after $5 \mathrm{minute}, 15$ minutes and 30 minutes in all groups ( $\mathrm{P}>0.05$ ). Conclusion: The authors found that dexmedetomidine is a safe and effective adjuvant to intrathecal bupivacaine-dexamethasone in multiparous women undergoing normal vaginal delivery.

Keywords: Bupivacaine, Dexamethasone, intrathecal.

Corresponding Author: Dr. Rakesh Kumar Gupta, Assistant Professor, Department of Anaesthesiology, FH Medical College, Tundla, India.

Received: 12/12/2019

Revised: $26 / 1 / 2020$

Accepted: 2/2/2020

\section{Introduction}

Labour pain is one of the difficult situations for the mother. Maternal and fetal hypoxemia may be the complications arising from painful uterine contractions because of hyperventilation. The associated catecholamine surge can cause maternal hyperglycemia, lipolysis, foetal acidosis and/or dysfunctional labor. ${ }^{[1]}$ Posttraumatic stress, postpartum depression and chronic pain resulting from intense labor pain. Effective analgesia during labor can avert or decrease these hazardous consequences. Intrathecal analgesia using local anaesthetics or opioids is a rapid onset and effective technique for pain management in laboring women. ${ }^{[2]}$ It provides a symmetrical neurologic blockade with a high success rate covering the episiotomy and forceps delivery. However, its major drawback is the limited analgesia duration. Only about half of the parturients who received combined spinal-epidural analgesia delivered during the spinal component of analgesia. $^{[3]}$

Epidural analgesia (EA) is widely used in relieving labor pain. Epidural bupivacaine is still the most widely used local anesthetic in obstetric analgesia. Its hyperbaric form is prepared by the addition of dextrose. ${ }^{[4]}$ It controls pain at the nerve level by interfering with the nerve membrane potential. It physically blocks the sodium channel by reversibly binding to receptors on the intracellular side of the membrane. An action potential cannot form and nerve impulse conduction cannot occur across the nerve membrane and up to the brain. The result of this is loss of sensation or numbness in the area where the drug is given. ${ }^{[5]}$

Morphine, fentanyl and dexmedetomidine are usually added as adjuvants to the local anaesthetics. ${ }^{[6]}$ These adjuvants can improve the neuraxial block characteristics while reducing the required local anaesthetic doses, thus minimizing the motor component of the block. ${ }^{[7]}$ The present study was conducted to assess the outcome of intrathecal analgesia in multiparous women undergoing vaginal delivery.

\section{Subjects and Methods}

The present study was conducted among 80 multiparous women age ranged 18- 40 years in the department of Anesthesiology. Patients with pre-existing or pregnancyinduced hypertension, abnormal foetal heart rate and diagnosed foetal abnormalities were excluded. The study was approved form the institutional ethical committee. All patients were also informed and their consent was obtained. 
Data such as name, age etc. were recorded. Patients were divided into 4 groups of 20 each. All patients received a 0.5 $\mathrm{ml}$ of intrathecal injection of $2.5 \mathrm{mg}$ bupivacaine $0.5 \%$ and 1 $\mathrm{ml}$ dexamethasone $4 \mathrm{mg}$ plus a $0.5 \mathrm{ml}$ adjuvant. The adjuvants in group I patients were $100 \mu \mathrm{g}$ morphine, $25 \mu \mathrm{g}$ fentanyl in group II, $5 \mu \mathrm{g}$ dexmedetomidine in group III and normal saline in group IV (control group).

The primary outcome was the duration of pain relief, the analgesia onset time, the maximum level of sensory block, the visual analog scale (VAS). The secondary outcomes were modified Ramsay sedation score (RSS), heart rate (HR), maternal adverse effects, FHR, APGAR score and umbilical cord gases. Results thus obtained were subjected to statistical analysis. A P-value of less than 0.05 was considered significant.

\section{Results}

\begin{tabular}{l}
\hline Table 1: Demographic profile of patients \\
\begin{tabular}{|l|l|l|l|l|l|}
\hline Groups & Group & $\begin{array}{l}\text { Group } \\
\text { II }\end{array}$ & $\begin{array}{l}\text { Group } \\
\text { III }\end{array}$ & $\begin{array}{l}\text { Group } \\
\text { IV }\end{array}$ & $\begin{array}{l}\text { P- } \\
\text { value }\end{array}$ \\
\hline Age (Years) & 28.1 & 27.4 & 27.2 & 28.2 & 0.15 \\
\hline Weight (Kgs) & 71.4 & 72.4 & 72.7 & 73.2 & 0.17 \\
\hline Height (cms) & 165.1 & 164.6 & 165.2 & 164.8 & 0.24 \\
\hline $\begin{array}{l}\text { Gestational } \\
\text { age (weeks) }\end{array}$ & 38.9 & 38.8 & 38.9 & 38.8 & 0.18 \\
\hline
\end{tabular}
\end{tabular}

[Table 1] shows that there was non- significant difference in mean age, weight, height and gestational age between all groups $(\mathrm{P}>0.05)$.

Table 2: Comparison of intrathecal block characteristics and labor progress

\begin{tabular}{|l|l|l|l|l|l|}
\hline Variables & $\begin{array}{l}\text { Group } \\
\text { I }\end{array}$ & $\begin{array}{l}\text { Group } \\
\text { II }\end{array}$ & $\begin{array}{l}\text { Group } \\
\text { III }\end{array}$ & $\begin{array}{l}\text { Group } \\
\text { IV }\end{array}$ & $\begin{array}{l}\text { P- } \\
\text { value }\end{array}$ \\
\hline $\begin{array}{l}\text { Duration of } \\
\text { analgesia } \\
\text { (mins) }\end{array}$ & 182.4 & 170.5 & 200.4 & 140.2 & 0.02 \\
\hline $\begin{array}{l}\text { Analgesia } \\
\text { onset (mins) }\end{array}$ & 3.9 & 2.8 & 2.7 & 4.5 & 0.01 \\
\hline $\begin{array}{l}\text { S1 sensory } \\
\text { regression time } \\
\text { (mins) }\end{array}$ & 181.4 & 157.4 & 185.3 & 130.6 & 0.04 \\
\hline $\begin{array}{l}\text { Modified } \\
\text { bromage scale } \\
5 \text { min after IT }\end{array}$ & 0 & 0 & 0 & 0 & 1 \\
\hline $\begin{array}{l}\text { Modified } \\
\text { bromage scale } \\
15 \text { min after IT }\end{array}$ & 0 & 0 & 0 & 0 & 1 \\
\hline $\begin{array}{l}\text { Modified } \\
\text { bromage scale } \\
30 \text { min after IT }\end{array}$ & 0 & 0 & 0 & 0 & 1 \\
\hline VAS & 1.3 & 1.6 & 1.6 & 3.1 & 0.01 \\
\hline
\end{tabular}

[Table 2] shows that the mean duration of analgesia in group I was 182.4 minutes, in group II was 170.5 minutes, in group III was 200.4 minutes and in group IV was 140.2 minutes. The onset of analgesia was 3.9 minutes, 2.8 minutes, 2.7 minutes and 4.5 minutes in group I, II, III and IV respectively. S1 sensory regression time (minutes) was 181.4, 157.4, 185.3 and 130.6 in group I, II, III and IV respectively. Modified Bromage scale 5 minutes, 15 minutes and 30 minutes after IT in all groups was 0.0. VAS was $1.3,1.6,1.6$ and 3.1 with significant differences in all groups $(\mathrm{P}<0.05)$.

Table 3: Neonatal parameters

\begin{tabular}{|l|c|c|c|c|c|}
\hline Variables & Group & Group & Group & Group & P - \\
\hline
\end{tabular}

\begin{tabular}{|l|l|l|l|l|l|}
\hline & I & II & III & IV & value \\
\hline APGAR 1 & 7.6 & 7.5 & 7.5 & 7.7 & 0.91 \\
\hline APGAR 5 & 8.8 & 8.8 & 8.8 & 8.7 & 0.82 \\
\hline $\begin{array}{l}\text { Umbilical pH } \\
\text { immediately after } \\
\text { delivery }\end{array}$ & 7.2 & 7.3 & 7.2 & 7.4 & 0.94 \\
\hline $\begin{array}{l}\text { Neonatal HR after 5 } \\
\text { minute }\end{array}$ & 138.2 & 140.2 & 141.2 & 142.3 & 0.81 \\
\hline $\begin{array}{l}\text { Neonatal HR after } \\
15 \text { minute }\end{array}$ & 138.5 & 140.5 & 142.5 & 142.8 & 0.96 \\
\hline $\begin{array}{l}\text { Neonatal HR after } \\
30 \text { minute }\end{array}$ & 140.5 & 142.6 & 144.6 & 143.8 & 0.62 \\
\hline
\end{tabular}

[Table 3] shows there was a non- significant difference in APGAR 1, 5, umbilical pH immediately after delivery, neonatal HR after 5minute, 15 minutes and 30 minutes in all groups $(\mathrm{P}>0.05)$.

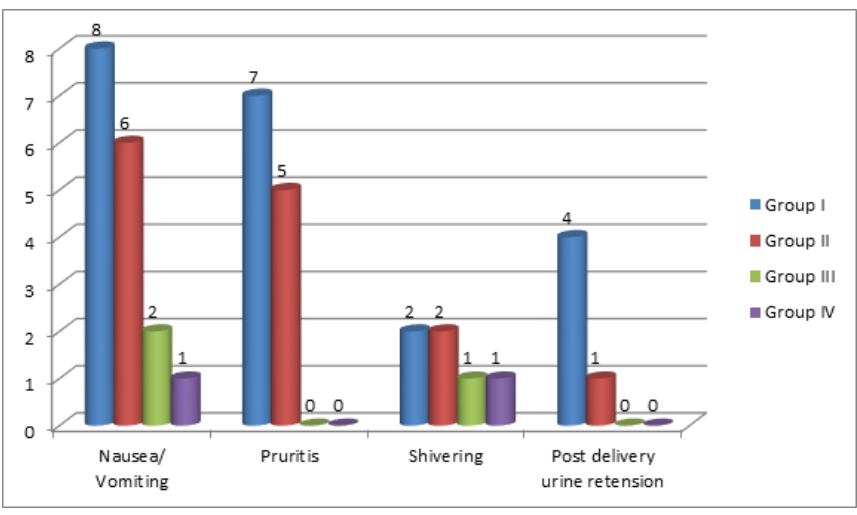

Figure 1: Side effects

[Figure 1] shows that nausea/ vomiting was seen in 8 in group I, 6 in group II, 2 in group III and 1 in group IV, pruritis 7 in group I, 5 in group II, shivering 2 in group I, 2 in group II and 1 each in group III and IV, post delivery urine retention was observed in 4 in group I and 1 in group II.

\section{Discussion}

Labor pain is excruciating and is a significant contributor to fear, stress, and anxiety. Painful uterine contractions lead to maternal hyperventilation and increased catecholamine concentration resulting in maternal and fetal hypoxemia. ${ }^{[8]}$ Labor pain when unrelieved can have adverse effects on the course of labor as well as on fetal wellbeing. Effective labor analgesia leads to better maternal and fetal outcomes. Relief of pain during labor endeavors to make the journey of labor safe and pleasant for both the mother and baby. ${ }^{[9]}$ The present study was conducted to assess the outcome of intrathecal analgesia in multiparous women undergoing vaginal delivery. In this study, all patients received a $0.5 \mathrm{ml}$ of intrathecal injection of $2.5 \mathrm{mg}$ bupivacaine $0.5 \%$ and $1 \mathrm{ml}$ dexamethasone $4 \mathrm{mg}$ plus an $0.5 \mathrm{ml}$ adjuvant. The adjuvants in group I patients were $100 \mu \mathrm{g}$ morphine, $25 \mu \mathrm{g}$ fentanyl in group II, $5 \mu \mathrm{g}$ dexmedetomidine in group III and normal saline in group IV (control group). Khaled et al, ${ }^{[10]}$ in their study included 140 multiparous women. Eligible women were given intrathecal bupivacaine-dexamethasone with dexmedetomidine (group D), fentanyl (group F), morphine (group M) or saline (placebo) (group C). The shortest analgesia onset time and the highest sensory levels were recorded in group D followed by 
group $\mathrm{F}$ then group $\mathrm{M}$ with statistical significance between all of them. Visual analogue scale values were comparable among groups $\mathrm{M}, \mathrm{F}$ and $\mathrm{D}(\mathrm{P}>0.05)$ at most of the measurement time points and at the peak of the last uterine contraction before delivery while being significantly lower than those in group $\mathrm{C}$.

We found that there was non- a significant difference in mean age, weight, height and gestational age between all groups $(\mathrm{P}>$ $0.05)$. The mean duration of analgesia in group I was 182.4 minutes, in group II was 170.5 minutes, in group III was 200.4 minutes and in group IV was 140.2 minutes. The onset of analgesia was 3.9 minutes, 2.8 minutes, 2.7 minutes and 4.5 minutes in group I, II, III and IV respectively. S1 sensory regression time (minutes) was 181.4, 157.4, 185.3 and 130.6 in group I, II, III and IV respectively. Modified Bromage scale 5 minutes, 15 minutes and 30 minutes after IT in all groups was 0.0. VAS was $1.3,1.6,1.6$ and 3.1 with significant differences in all groups $(\mathrm{P}<0.05)$.

Mathur et al, ${ }^{[1]}$ included 60 women which were divided into Group SA $(n=30)$ received an intrathecal injection of $0.5 \%$ hyperbaric bupivacaine $2.5 \mathrm{mg}$ and fentanyl $25 \mu \mathrm{g}$ and group $C(n=30)$ who refused to give consent for neuraxial analgesia. It was found that the duration of the active phase of the first stage of labor was shortened in group SA as compared to group C (115.50 vs. $134.0 \mathrm{~min}, \mathrm{P}<0.05)$. The duration of the second stage of labor was prolonged in group SA as compared to group $\mathrm{C}(18.03$ vs. $10.13 \mathrm{~min}, \mathrm{P}<0.05)$. The rate of cervical dilation was faster in group SA as compared to group C (3.021 vs. $2.486 \mathrm{~cm} / \mathrm{h}, \mathrm{P}<0.05)$. Mean visual analog score, pulse rate, and mean arterial pressure were significantly decreased as compared to the baseline in group SA. No significant changes were noted in the fetal heart rate as compared to the baseline in both groups.

We found that there was a non- significant difference in APGAR 1, 5, umbilical pH immediately after delivery, neonatal $\mathrm{HR}$ after 5 minute, 15 minute and 30 minutes in all groups ( $\mathrm{P}>0.05)$. Although neuraxial analgesia may be associated with some short-term maternal side effects, it does not worsen fetal acidosis and may partially protect the foetus from foetal hypoxia. Additionally, neuraxial analgesia was found to be linked with better neonatal Apgar scores and improvement in acid-base balance compared to systemic analgesia and even in comparison to no analgesia. ${ }^{[12]}$

\section{Conclusion}

Authors found that dexmedetomidine is a safe and effective adjuvant to intrathecal bupivacaine-dexamethasone in multiparous women undergoing normal vaginal delivery.

\section{References}

1. AbdElBarr T, Elshalakany NA, Shafik YM. Single-dose spinal analgesia: Is it a good alternative to epidural analgesia in controlling labour pain? Egy J Anaesth. 2014;30:241-6.

2. Missant C, Teunkens A, Vandermeersch E, Van de Velde M. Intrathecal clonidine prolongs labour analgesia but worsens fetal outcome: A pilot study. Can J Anaesth. 2004;51:696.

3. Aguilar-Montiel M, Carrillo-Torres O. Remifentanil and dexmedetomidine as an alternative to regional analgesia in obstetrics. Rev Med Hosp Gen Mex. 2017;80:67-70.

4. Swain A, Nag DS, Sahu S, Samaddar DP. Adjuvants to local anesthetics: Current understanding and future trends. World J Clin Cases. 2017;5:307.

5. Fyneface-Ogan S, Gogo Job O, Enyindah CE. Comparative effects of single-shot intrathecal bupivacaine with dexmedetomidine and bupivacaine with fentanyl on labor outcome. ISRN Anesthesiol. 2012.

6. Hess PE, Vasudevan A, Snowman C, Pratt SD. Small dose bupivacainefentanyl spinal analgesia combined with morphine for labor. Anaesth Analg. 2003;97:247-52.

7. Carvalho B. Respiratory depression after neuraxial opioids in the obstetric setting. Anaesth Analg. 2008;107:956-61.

8. Cascio M, Pygon B, Bernett C, Ramanathan S. Labour analgesia with intrathecal fentanyl decreases maternal stress. Can J Anaesth. 1997;44:605-9.

9. Kim JE, Kim NY, Lee HS, Kil HK. Effects of intrathecal dexmedetomidine on low-dose bupivacaine spinal anesthesia in elderly patients undergoing transurethral prostatectomy. Biol Pharm Bull. 2013;36:959-65.

10. Khaled GM, Sabry AI. Outcomes of intrathecal analgesia in multiparous women undergoing normal vaginal delivery: A randomized controlled trial. Indian Journal of Anaesthesia. $2020 \mathrm{Feb}$;64(2):109.

11. Mathur P, Jain N, Prajapat L, Jain K, Garg D, Khandelwal V. Effect of intrathecal labor analgesia using fentanyl $25 \mu \mathrm{g}$ and bupivacaine $2.5 \mathrm{mg}$ on the progress of labor. J Obstet Anaesth Crit Care 2017;7:47-51.

12. Bani-Hashem N, Hassan-Nasab B, Pour EA, Maleh PA, Nabavi A, Jabbari A. Addition of intrathecal Dexamethasone to Bupivacaine for spinal anesthesia in orthopedic surgery. Saudi J Anaesth. 2011;5:382.

Copyright: ( $)$ the author(s), 2020. It is an open-access article distributed under the terms of the Creative Commons Attribution License (CC BY 4.0), which permits authors to retain ownership of the copyright for their content, and allow anyone to download, reuse, reprint, modify, distribute and/or copy the content as long as the original authors and source are cited.

How to cite this article: Masih SM, Gupta RK. Assessment of Outcome of Intrathecal Analgesia in Multiparous Women Undergoing Vaginal Delivery. Acad. Anesthesiol. Int. 2020;5(1):153-155.

DOI: dx.doi.org/10.21276/aan.2020.5.1.31

Source of Support: Nil, Conflict of Interest: None declared. 